\title{
Filosofía en el Chile colonial: el curso de animástica de fray Juan de Fuica*
}

\section{Philosophy in colonial Chile: the animastics course of friar Juan de Fuica}

\author{
Abel Aravena Zamora \\ Universidad de Barcelona, España.
}

Recibido: $19 / 06 / 2015$

Aceptado: 30/11/2015

\section{Resumen}

Este artículo pretende exponer los contenidos generales del curso de animástica dictado por el fraile franciscano Juan de Fuica en el Colegio San Diego de Alcalá de Santiago de Chile, en mayo de 1689. Para ello, presentamos primero una nota biográfica del autor que incluye información relativa a la trayectoria académica y administrativa dentro de la Orden de los Frailes Menores y, luego, analizamos los aspectos más relevantes de la doctrina psicológica ad mentem Scoti expuestos en esta obra manuscrita inédita, la que constituye un testimonio exclusivo de la enseñanza filosófica de la época. Creemos que el principal aporte de este trabajo es visibilizar el patrimonio filosófico colonial del país y, con ello, llenar una gran laguna en la historia de la filosofía chilena.

Palabras clave: animástica, escotismo, filosofía chilena, filosofía colonial, manuscrito.

\begin{abstract}
This article aims to put forward the general contents of the animastics course dictated in May 1689 by the Franciscan friar Juan de Fuica at San Diego de Alcalá College, Santiago de Chile. In order to do that, first, we present a biographical note on the author that includes information relating to his academic and administrative

\footnotetext{
* Esta investigación ha contado con el financiamiento del Programa Conicyt - Becas Chile. El autor agradece a fray Rigoberto Iturriaga, Archivero de la Provincia Franciscana en Santiago de Chile, y a fray Alexis Escárate Hermosilla por su cooperación en el desarrollo de este trabajo.
} 
career within the Order of the Friars Minor. Second, we analyze the most relevant aspects of the ad mentem Scoti psychological doctrine presented in this unreleased manuscript, which is an exclusive testimony of philosophy teachings at that time. We believe that the main contribution of this paper is to turn visible the colonial philosophical heritage of the country and, thereby, to fill a gap in the history of Chilean philosophy.

Keywords: animastics, scotism, Chilean philosophy, colonial philosophy, manuscript.

\section{Nota biográfica}

Fray Juan de Fuica de Huerta nació alrededor del año 1660 en la ciudad de La Serena (IV región), en el norte de Chile, en el seno de una noble familia cristiana relacionada íntimamente con la historia de la ciudad y, también, con la historia del país.

El fraile fue hijo del Capitán don Gabriel de Fuica y de doña María de Huerta, ambos nacidos en La Serena. Por línea paterna, fue nieto de Mariana de Carvajal, natural de la misma ciudad, y del Maestre de Campo don Gabriel de Fuica ( $† 1657)$, español natural de Bilbao, quienes habían contraído matrimonio en 1635 en La Serena. Su abuelo Gabriel fue Alcalde ordinario, Provincial y Corregidor de la ciudad y llegó a ser Mayordomo mayor de la Cofradía de Nuestra Señora del Rosario, además de "dueño de un entierro perpetuo para sí y sus descendientes, en la capilla mayor del Convento de Santo Domingo; declarado Hermano y benefactor de la Orden, 1645". Asimismo, por línea materna paterna, fray Juan de Fuica fue bisnieto de Francisco de Aguirre, quien había llegado a Chile en 1540 junto a Pedro de Valdivia y participó en la fundación de las ciudades de Santiago (1541) y La Serena (1549) ${ }^{1}$.

Según leemos en las declaraciones de los testigos en su toma de hábito, fechadas en mayo de $1676^{2}$, Fuica descendía de una familia de cristianos viejos de la ciudad, que "no de moros ni infieles" y "no había cometido delitos que la ley prohibiera -como son-crímenes, hurtos u otros semejantes por los cuales deba ser castigado"4.

Fue declarado Predicador en $1683^{5}$ y dos años más tarde fue instituido Confesor y designado Lector de regla y Maestro de estudiantes de artes en el Convento de

\footnotetext{
${ }^{1}$ ESPEJO, J. Nobiliario de la Antigua Capitanía General de Chile. Santiago de Chile: Imprenta Universitaria, 1917, p. 111.

${ }^{2}$ Informes de Novicios (1603 - 1739), Archivo de la Provincia Franciscana, foja 16. Cf. CAZANOVA, F. Historia de la Recoleta I. Santiago de Chile: Publicaciones del Archivo Franciscano, nº 56, 1998, p. 168.

${ }^{3}$ Informes de Novicios (1603 - 1739), Archivo de la Provincia Franciscana, foja 17v.

${ }^{4}$ Informes de Novicios (1603 - 1739), Archivo de la Provincia Franciscana, foja 16.

${ }_{5}^{5}$ ITURRIAGA, R. Tablas Capitulares de la Provincia Franciscana (XVII). Santiago de Chile: Publicaciones del Archivo Franciscano, no 69, 2001, p. 48.
} 
Nuestra Señora del Socorro de la ciudad de Santiago ${ }^{6}$. En abril de 1687 le encontramos aún en el mismo Convento con el cargo de Lector de artes, como se indica en la portada general del libro que contiene los cinco Comentarios dictados por el fraile, detallando su condición de "antiguo Maestro de estudiantes"

Durante 1688 debió de ser trasladado al colegio San Diego de Alcalá que la Orden mantenía en Santiago, pues en el título de los comentarios a la Physica, fechados en noviembre de ese año, aparece ya enseñando en dicha institución ${ }^{8}$. Sin embargo, es en junio de 1689 cuando aparece oficialmente designado como Lector de artes ${ }^{9}$. Podemos confirmar esto último con la información indicada en la portada de los Comentarios Acerca del alma: Profesor de la cátedra de artes, 14 de mayo de $1689^{10}$. Meses después, en octubre de ese mismo año, fue designado Lector de moral y Maestro de estudiantes teólogos en el mismo colegio ${ }^{11}$.

Un par de años más tarde, el fraile fue trasladado a la ciudad de Penco, ubicada a un poco más de cuatrocientos kilómetros al sur de Santiago. Allí permaneció algunos años, probablemente entre 1691 y 1695-6, desempeñándose en diferentes cargos: Lector de nona, Maestro de estudiantes, Lector de moral, Predicador mayor y Rector de la Tercera Orden en el Convento de la ciudad ${ }^{12}$. Cabe señalar que unos veinte años después, en 1710, el franciscano vuelve nuevamente a la ciudad, esta vez como Guardián del Convento ${ }^{13}$.

En 1697 le hallamos de regreso en Santiago, enseñando en el colegio San Diego como Lector vespertino - mora $1^{14} \mathrm{y}$, dos años después, fue elegido Definidor y designado Lector vespertino - regla y Lector de mística en el mismo colegio ${ }^{15}$.

\footnotetext{
${ }^{6}$ ITURRIAGA, R. Ibid., p. 52.

7 "Olim Magistrum studentium; nunc autem in Magno Beatae Mariae de Succursu Civitatis Sancti Jacobi Artium Cathedrae Moderatorem".

8 "Olim Magistrum Studentium, nunc autem in Chilleno Sancti Didaci de Alcalá Collegio Artium Cathedrae Moderatorem".

${ }^{9}$ ITURRIAGA, R. Tablas Capitulares de la Provincia Franciscana (XVII). Santiago de Chile: Publicaciones del Archivo Franciscano, n 69, 2001, p. 62.

10 “...et in hoc Sancti Didaci de Alcala Collegio Artium Cathedrae Professorem".

${ }^{11}$ ITURRIAGA, R. Tablas Capitulares de la Provincia Franciscana (XVII). Santiago de Chile: Publicaciones del Archivo Franciscano, no 69, 2001, p. 68.

${ }^{12}$ ITURRIAGA, R. Ibid., pp. 74, 79, 85, 89.

${ }^{13}$ RAMÍREZ, H. Fuentes para la historia franciscana II. Libros Becerros de Actas y Decretos del Venerable Definitorio de la Provincia Franciscana de la Santísima Trinidad de Chile. Índice de Materias y Extractos. Siglo XVIII (1700-1734). Santiago de Chile: Publicaciones del Archivo Franciscano, nº 23 , 1992, p. 8.

${ }^{14}$ ITURRIAGA, R. Tablas Capitulares de la Provincia Franciscana (XVII). Santiago de Chile: Publicaciones del Archivo Franciscano, nº 69, 2001, pp. 103, 109.

${ }^{15}$ ITURRIAGA, R. Ibid., pp. 113, 117.
} 
Ya en el siglo XVIII, en marzo de 1707 fue declarado Lector Jubilado ${ }^{16}$, lo que indicaba que el fraile se hacía merecedor de la jubilación al haber cumplido con el requisito de enseñar durante quince años como profesor de una cátedra.

Entre octubre de 1724 y 1726 fray Juan de Fuica fue Guardián y Rector del colegio San Diego de Alcalá ${ }^{17}$ y en febrero de 1728 fue nombrado Presidente de una comisión encargada de redactar unas nuevas leyes particulares para dicha institución ${ }^{18}$. Este último hecho, importantísimo para entender su relevancia dentro de la Orden, derivó probablemente en la redacción de las segundas Constituciones del colegio San Diego (1732) $)^{19}$.

Durante un período de doce años, entre 1721 y 1733, se desempeñó como Examinador de predicadores, confesores y audientium ${ }^{20} \mathrm{y}$, paralelamente, entre $1728 \mathrm{y}$ 1729, fue el Cronologus Provinciae, vale decir, el fraile responsable de compilar y redactar las crónicas o la historia cronológica de un convento de una Provincia Seráfica ${ }^{21}$.

\section{Los Comentarios a los tres libros Acerca del alma según nuestro Doctor Sutil Duns Scoto, Príncipe de los teólogos}

El curso de animástica de fray Juan de Fuica está compuesto por sus Comentarios a los tres libros Acerca del alma, dictados en el Colegio San Diego de Alcalá de Santiago de Chile y con fecha del 14 de mayo de 1689.

Como ya hemos avanzado, este texto se encuentra en el libro manuscrito que actualmente resguarda el Archivo Provincial de la Orden en Santiago y que se titula Commentaria phylosophica ad mentem Doctoris Subtilissimi Patris Fratris Joannis

\footnotetext{
${ }^{16}$ RAMÍREZ, H. Fuentes para la historia franciscana II. Libros Becerros de Actas y Decretos del Venerable Definitorio de la Provincia Franciscana de la Santisima Trinidad de Chile. Índice de Materias y Extractos. Siglo XVIII (1700-1734). Santiago de Chile: Publicaciones del Archivo Franciscano, nº 23, 1992, p. 4.

${ }^{17}$ Actas del Definitorio, ff. 286, 305r.

${ }^{18}$ RAMÍREZ, H. Fuentes para la historia franciscana II. Libros Becerros de Actas y Decretos del Venerable Definitorio de la Provincia Franciscana de la Santísima Trinidad de Chile. Índice de Materias y Extractos. Siglo XVIII (1700-1734). Santiago de Chile: Publicaciones del Archivo Franciscano, nº 23, 1992, pp. 33-34.

${ }^{19}$ Cf. MEDINA, J. T. La Instrucción Pública en Chile desde sus orígenes hasta la fundación de la Universidad de San Felipe. Santiago de Chile: Imprenta Elzeviriana, 2 volúmenes, 1905, v. 1, pp. CCCLVI ss, donde revisa dichas Constituciones.

${ }^{20}$ Actas del Definitorio, Archivo de la Provincia Franciscana, ff. 254, 265, 349r, 351.

${ }^{21}$ Actas del Definitorio, Archivo de la Provincia Franciscana, ff. 322r, 335. Cf. RAMÍREZ, H. Fuentes para la historia franciscana IV. Libros Becerros de Actas y Decretos del Venerable Definitorio de la Provincia Franciscana de la Santísima Trinidad de Chile. Índice de Materias y Extractos. Siglo XVIII (1765-1799). Santiago de Chile: Publicaciones del Archivo Franciscano, nº 29, 1993, p. 64.
} 
Duns Scoti Sacratissimi Ordinis Minorum et Theologorum Principis; que contiene también otros cuatro comentarios ad mentem Scoti ${ }^{22}$.

Todos ellos fueron dictados por el fraile en dos de los centros que la Orden Franciscana mantenía en la ciudad de Santiago durante la época colonial: el primero en el Convento del Socorro y los restantes en el colegio San Diego de Alcalá23. En su conjunto, los comentarios abarcan el período del curso trienal 1687-1689.

El copista de todos los comentarios fue fray Francisco de Morales -según él mismo lo indica en cada una de las portadas- en su calidad de alumno del mismo colegio y discípulo del lector Juan de Fuica. Vale la pena mencionar aquí que probablemente ambos frailes eran naturales de la ciudad de La Serena. Y, asimismo, que diez años después de comenzar la redacción del primero de los comentarios, esto es, en 1697, ambos religiosos vuelven a encontrarse en el colegio San Diego, esta vez desempeñándose como profesores.

Los Comentarios Acerca del alma presentan un marcado interés por la psicología racional, lo que es en general una característica de la enseñanza escolástica. En ellos, el fraile expone y estudia los temas que son ya clásicos desde Aristóteles: la esencia y las potencias del alma en general y en particular, los actos y los objetos, los sentidos externos e internos, la espiritualidad e inmortalidad del alma, y la naturaleza del conocimiento y del intelecto.

De acuerdo con nuestras investigaciones, este curso de animástica del franciscano de La Serena es el más antiguo entre los cursos de autor chileno que en la actualidad se conservan sobre esta materia ${ }^{24}$. Cabe destacar que si consideramos globalmente

\footnotetext{
${ }^{22}$ Los cuatro primeros comentarios que incluye el libro se encuentran en el siguiente orden: Commentaria in Universam Aristotelis Logicam una cum distinctionibus et quaestionibus iuxta mentem et doctrinam Doctoris Subtilis Ioannis Duns Scoti Theologorum Facile Principis [Convento del Socorro, 1687]; Commentaria in Universam Aristotelis Metaphysicam una cum distinctionibus et quaestionibus iuxta mentem et doctrinam noster Subtilis Doctoris Fratris Ioannis Duns Scoti Theologorum Facile Principis [Convento del Socorro, 1687]; Commentaria in octo libros Physicorum Aristotelis Stagiritae una cum distinctionibus et quaestionibus iuxta mentem et doctrinam nostri Subtilissimi Doctoris Fratris Ioannis Duns Scoti Theologorum Facile Principis [Colegio San Diego de Alcalá, 1688]; y Commentaria in duos libros Aristotelis De generatione et corruptione secundum mentem nostri Doctoris Subtilis Fratris Ioannis Duns Scoti Theologorum Principis [Colegio San Diego de Alcalá, 1689].

${ }^{23}$ Cf. ITURRIAGA, R. EL Colegio San Diego de Alcalá. Santiago de Chile: Publicaciones del Archivo Franciscano, $n^{\circ} 4,1990$.

${ }^{24}$ Cf. ASTORQUIZA, F. Bio-Bibliografía de la filosofía en Chile desde el siglo XVI hasta 1980. Santiago de Chile: Barcelona Empresa Industrial Gráfica, 1982; REDMOND, W. Bibliography of the Philosophy in the Iberian Colonies of America. The Hague: Martinus Nijhoff, 1972; HANISCH, W. En torno a la Filosofia en Chile (1594 - 1810). Santiago de Chile: Ediciones Historia, Universidad Católica de Chile, 1963; QUILES, I. "Manuscritos filosóficos en la época colonial en Chile". Ciencia y Fe, pp. 39-61, 1953; DONOSO, R. "Inventario de la Colección del Fondo Antiguo del Archivo Nacional de Santiago de Chile". Handbook of Latin American Studies, pp, 547-572, 1937; MEDINA, J. La Instrucción Pública en Chile desde sus orígenes hasta la fundación de la Universidad de San Felipe. Santiago de Chile: Imprenta Elzeviriana, 2 volúmenes, 1905; VALENZUELA, P. Los Regulares en la
} 
la información recogida sobre el fraile podríamos pensar que en ellos se expone una mentalidad juvenil, propia de los inicios de su magisterio. Asimismo, si bien hallamos errores ortográficos y gramaticales que no dan cuenta de una revisión cuidadosa de los textos, nos inclinamos a pensar que el libro que reúne los comentarios del trienio indicado podría ser el esfuerzo del fraile por responder a las demandas de la orden de unificar las materias requeridas por los estudiantes de artes. De manera que podría constituir un esbozo para un eventual Manual de estudios de la Provincia chilena ${ }^{25}$.

Desde esta perspectiva, creemos que el valor de este curso manuscrito radica en que es un testimonio único no sólo de la tradición escotista nacional de finales del $\mathrm{XVII}^{26}$, sino en general de la enseñanza filosófica de la época colonial chilena ${ }^{27}$. Por ello, en las páginas que siguen, intentaremos rescatar los rasgos fundamentales de las enseñanzas animásticas del curso del franciscano chileno.

\section{Su doctrina psicológica}

Fray Juan de Fuica nos indica en el preludio de los Comentarios Acerca del alma

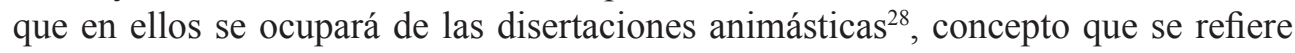
a aquellas materias relativas al alma sobre las que debe ocuparse la filosofía. Por ello -señala- su contenido es absolutamente especulativo y su objeto de estudio es el alma en general. En este sentido, la animástica viene a ser la disciplina que en la terminología actual conocemos como psicología.

El fraile de La Serena comienza por definir qué es el alma en general, para lo que, primero, establece que la existencia del alma es una verdad notoria y evidente per se. Luego analiza algunas definiciones que de ella han sido transmitidas, valiéndose expresamente del legado aristotélico desde la interpretación escotista.

Iglesia y en Chile. Roma: Imprenta Tiberina de Federico Setth, 1900.

${ }^{25}$ Cf. MEDINA, J. T. La Instrucción Pública en Chile desde sus orígenes hasta la fundación de la Universidad de San Felipe. Santiago de Chile: Imprenta Elzeviriana, 2 volúmenes, 1905, v. 1, p. CXXXVIII.

${ }^{26}$ Cf. ITURRIAGA, R. "El Escotismo en Chile". Anuario de Historia de la Iglesia en Chile. Santiago de Chile: Seminario Pontificio Mayor, V. 8, pp. 37-58, 1990; sobre el escotismo cultivado posteriormente en la Universidad de San Felipe, véase MEDINA, J. Historia de la Real Universidad de San Felipe de Santiago de Chile. Santiago de Chile: Imp. y Lit. Universo. 2 Tomos, 1928, especialmente capítulos IV, VII y X del tomo 1. Asimismo, en la p. 519 se encuentra un listado con todos los profesores de la Cátedra de Escoto en la Universidad entre los años 1767 y 1802.

${ }^{27}$ Respecto de la Universidad de San Felipe, véase MEDINA, J. Ibid.; FUENZALIDA, A. Historia del desarrollo intelectual en Chile (1541 - 1810). (Enseñanza Pública i Cultura Intelectual). Santiago de Chile: Imprenta Universitaria, 1903, capítulo I.

28 "Animastice" sería un neologismo acuñado por Escoto para calificar el acto del alma intelectiva en tanto que acto psicológico. Cf. SONDAG, G. "Jean Duns Scot sur la connaissance intuitive intellectuelle (Cognitio Intuitiva)”. Veritas: Revista de Filosofía (Porto Alegre), v. 53, 2008, nota al pie 2, p. 32. 
Nos entrega en primer lugar esta definición: "el alma es el acto primero de un cuerpo natural orgánico que tiene vida en potencia" ${ }^{\text {"29. }}$. Respecto de dicha definición, Fuica nos aclara que "acto primero" se dice genéricamente, puesto que la razón de acto primero se predica unívocamente de todas las formas substanciales; que se dice "de un cuerpo natural orgánico", porque el alma es el acto de la materia, no en cualquier manera, sino de la materia organizada a partir de una forma de corporeidad [forma corporeitatis]; que se dice "que tiene vida en potencia" y que aquella parte "vida" denota a la vida no substancial, a la vida accidental, es decir, la operación vital que un ser vivo puede producir a partir de la fuerza del alma, y que tiene vida en potencia dado que a partir de la fuerza del alma se vuelve capaz de operar vitalmente.

En segundo lugar, el franciscano nos indica otra definición también transmitida por el Estagirita: "el alma es aquello por lo que primariamente vivimos, sentimos, nos movemos de lugar e inteligimos" ${ }^{\prime 30}$. A continuación, el fraile acepta la validez de ambas definiciones.

Fray Juan de Fuica argumenta luego que únicamente los seres vivos tienen cuerpo orgánico, pues sólo en los seres vivientes se encuentran las distintas afecciones, es decir, los diversos órganos para el ejercicio de la vida, dado que los órganos son los instrumentos de la vida. En cambio, los seres inanimados no tienen aquellos órganos, por lo que no pueden operar vitalmente ni tampoco vivir. Por ello, se tiene que los órganos que están en un cadáver no son en rigor órganos, sino que en cierto modo son simulacros de ellos. Así, recurriendo a la autoridad del Filósofo para probar su argumento, el fraile nos dice que "Aristóteles dijo que el dedo muerto y el vivo son dedos de manera equivoca"31.

El franciscano explica que para la organización substancial de los cuerpos de los seres vivos se requiere en la materia tanto de la organización accidental como de la substancial y agrega que la manera de llevar a cabo dicha organización comienza por los accidentes y se consuma por la organización substancial, gracias a una particular forma substancial: la forma de corporeidad.

El fraile introduce en este punto de la disertación este concepto fundamental para entender la organización substancial de los cuerpos, que es también un elemento clave en la doctrina metafísica y psicológica de la filosofía del Sutil. Por ello, nos detendremos a revisar qué es lo que explica respecto de la forma de corporeidad.

Fray Juan de Fuica escribe a modo de introducción sobre este concepto: "Esta cuestión es bastante célebre entre las cuestiones filosóficas", y seguidamente desarrolla con detención dicha noción, su diferencia con el alma y la relación de aquella con el cuerpo de un ser viviente.

\footnotetext{
${ }^{29}$ Cf. ARISTÓTELES, Acerca del alma, II, 1, 412a27.

${ }^{30} \mathrm{Cf}$. ARISTÓTELES, Acerca del alma, II, 2, 414a12-13.

${ }^{31} \mathrm{Cf}$. ARISTOTELES, Metafísica, Z, $1035 \mathrm{~b} 25$.
} 
Así, encontramos que anota: "En efecto, la forma orgánica o de corporeidad no es específica, completa el ser específico y acabado de la cosa, puesto que de ella y la materia prima resulta un compuesto substancial incompleto, que es per se potencia respecto de la forma última de los seres vivos". Agrega que al ser dirigida por la naturaleza, en tanto algo potencial respecto del alma, la forma de corporeidad es diversificada esencialmente según la distinción esencial del alma, a la que se ordena perse.

Vemos que dicho pasaje del fraile chileno es coherente con las doctrinas psicológicas de Escoto, pues según éste la forma de corporeidad antecede natural o lógicamente -y no de una manera temporal- a la llegada simultánea de las almas intelectiva, vegetativa y sensitiva, que son creadas e infundidas inmediatamente por Dios.

La forma de corporeidad da a la materia el ser corpóreo, informa sus elementos materiales, compone y dispone junto con la materia al cuerpo, que entonces queda apto para la recepción del alma intelectiva. Por ello, la forma de corporeidad sólo es una forma disponente e imperfecta o incompleta, pues es completada y perfeccionada por el alma intelectiva que se añade. Esta última es privativa del ser humano y perfecciona completamente al cuerpo, siendo así su propia forma constitutiva, a diferencia de la forma de corporeidad que sólo dispone, perfecciona y domina el compuesto materia-forma.

Del mismo modo, la forma de corporeidad, al ser una forma imperfecta, permanece por sí sola en el cuerpo después de la muerte de un ser vivo, aunque no puede dominar sobre aquel por demasiado tiempo, por lo que el cadáver pronto se disuelve en sus propios elementos. Por esta razón, un cadáver no es una entidad en el sentido pleno del término. No obstante, de aquí se deriva el problema de si, en él, la forma de corporeidad está en el mismo estado que cuando estaba incluida bajo la forma de la totalidad animada.

De acuerdo con lo anterior, se sigue que la forma de corporeidad difiere realmente del alma, puesto que sólo la dispone y permanece en el compuesto, mientras que el alma es separada del cuerpo por la muerte. Respecto a esto, hallamos que el fraile de La Serena escribe acerca del cuerpo de Cristo: "era el mismo cuerpo de Cristo en el útero de la virgen, colgado en la cruz, el que yació en el sepulcro y el que resucitó: por tanto, era el mismo el cuerpo de Cristo muerto y vivo, en aquel momento y de tal modo. Pero supuesto que no se de la forma de corporeidad del cuerpo conservado después de la muerte de Cristo el Señor esto no sería verdad"

Fray Juan de Fuica señala también el error de Santo Tomás y sus discípulos al afirmar que la razón del cuerpo orgánico proviene del alma (Summa Theologiae I, q. 76, art. 4) y no de la forma de corporeidad y, en cambio, declara seguir en esto al Sutil y a otros autores de la tradición escotista: Antonio Andrés, Basolius, Juan de Rada, Alfonso Briceño, Juan Merinero López y el Padre Poncio.

En este contexto, vemos que explica la relación que se da entre la forma de corporeidad y la concepción de un ser vivo, descartando de plano la intervención de 
cualquier tipo de semen en el proceso. Indica que la causa productora de la forma de corporeidad en los seres vivientes que son concebidos por una madre es el cuerpo orgánico de ella, que introduce una forma semejante en la materia del semen. En cambio, en los seres vivientes que no son concebidos por una madre, la causa eficiente de la forma de corporeidad es Dios y las demás causas universales.

El franciscano chileno argumenta que para negar la existencia de la forma de corporeidad no basta con plantear la identidad de la materia con los accidentes, pues la materia está compuesta por dos formas esencialmente diversas que se dicen la misma; no obstante, la identidad o la distinción del compuesto substancial se toma por la forma y no por la materia en acto por los accidentes. Por ello, -nos dice- aunque la materia se identifique con los accidentes, si las formas se distinguen esencialmente, también los compuestos se distinguirán de la misma manera.

Una vez establecido que la organización substancial no proviene del alma, sino que la entrega la forma de corporeidad, el fraile aclara que los cuatro humores del cuerpo (sangre, flema, bilis amarilla y bilis negra) tampoco son informados por el alma, sino que son productos de las propias formas substanciales completas. En la misma línea, nos indica que los dientes, los cabellos y las uñas no son animados, puesto que el aumento de ellos no es vital y no procede del alma ni de un principio interno. Para corroborar lo anterior, el franciscano recurre a la autoridad de Aristóteles cuando éste escribe que "los cabellos crecen en muchos muertos" 32.

Siguiendo siempre las doctrinas del Sutil, fray Juan de Fuica entrega una última precisión acerca del alma en general. Argumenta que ésta se divide, en forma unívoca y suficiente, en vegetativa, sensitiva y racional, así como en sus propias especies. Apoyándose en la distinción escotista entre el orden de la formalidad y el del ser actual [distinctio ex natura rei], explica que "si el alma vegetativa, sensitiva y racional son tomadas físicamente como fluyen en el mundo real, esencialmente se distinguen siempre". De manera que a nivel físico, en el orden actual, vale decir, tal como aparece en el mundo real, tenemos que considerar esta distinción esencial.

Sin embargo, al respecto agrega que: "si hablamos metafisicamente de acuerdo con lo que divide el grado genérico de los seres vivos en vegetativo, sensitivo y racional, estas tres almas no se distinguen como tres formas fisicas, sino como tres predicados metafisicos subordinados en cierto modo en línea categorial, así como se distinguen el animal, el ser vivo y el hombre..."33.

De este modo, tenemos que el alma sensitiva es formalmente vegetativa en abstracto [ut quo], es decir que por su manifestación constituye el ser vivo vegetal y sensible, lo que también se dice con mayor razón sobre el alma racional. Por tanto -nos dice-conforme al aumento gradual de los seres vivos no se tiene una multiplicidad de almas en cada uno de ellos.

\footnotetext{
${ }^{32}$ Cf. ARISTÓTELES, Reproducción de los animales, II, 6, 745a18-19.

${ }^{33}$ Cf. SCOTUS, Ord. L. IV, d. 44, q. 1, n. 4.
} 
Gracias a esta distinción metafísica fundamental [distinctio ex natura rei] puede postularse que cada ser vivo posee sólo un alma, aunque en ella se distinguen formalmente aquellos tres grados. No obstante, Fuica nos aclara que el objeto adecuado principal de la animástica es el alma racional, puesto que es la superior entre todas.

El franciscano de La Serena estudia el alma racional en una Distinción exclusiva. Allí encontramos mayormente una argumentación teológica de su naturaleza, que se apoya en la autoridad católica y la fe en las escrituras. Siguiendo el modelo aristotélico, el fraile comienza por definirla como "el acto primero de un cuerpo natural orgánico que tiene vida intelectiva en potencia" y la distingue de la substancia angélica, pues el alma es la forma informante de un cuerpo orgánico, del que el ángel carece. A continuación, afirma que el alma racional es enteramente espiritual, siendo ésta una verdad definida en el Concilio de Letrán ${ }^{34}$, en el capítulo acerca de la Santa Trinidad.

Explica que el alma racional sólo tiene composición metafísica según el género y la diferencia y que no es producida en virtud del semen, ni angélico ni el de otra criatura cualquiera, sino que es creada en forma inmediata por Dios. Argumenta que el alma racional, al ser espiritual, no depende de la materia ni está precontenida en aquella y, por lo tanto, no es extraída, sino creada. Sin embargo, -aclara- no es producida fuera del cuerpo ni después de la producción del cuerpo, sino en el momento en que el cuerpo orgánico es conformado en última instancia. No obstante lo anterior, el fraile vuelve a insistir en que el alma intelectiva sólo se diferencia formalmente $-\mathrm{y}$ no realmente- de la sensitiva y vegetativa.

La inmortalidad del alma racional también es fundamentada por el fraile apelando a la autoridad de las escrituras. Por una parte, afirma la inmortalidad del alma de acuerdo con la fe, como está definido en el sexto sínodo y en el Concilio de Letrán, y escribe que: "se prueba de acuerdo con la Sagrada Escritura de Mateo 10: 'No tengáis miedo de los que matan el cuerpo, pero no pueden matar el alma ${ }^{35}$, y Juan 12: 'el que aborrece su alma en este mundo, la conserva para la vida eterna' ${ }^{36}, y$ de acuerdo con ello en el libro de la Sabiduría: 'las almas de los justos están en las manos de Dios' 37 ". Y, por otra parte, el alma racional es inmortal de acuerdo con su propia naturaleza, como consta en la epístola de san Pablo a los romanos: "El espíritu da testimonio a nuestro espiritu",38.

De acuerdo con lo anterior, tenemos que si el alma es un ser per se e independiente del cuerpo es porque Dios le da este esse per se que caracteriza a la substancia.

\footnotetext{
${ }^{34}$ Se refiere al IV Concilio de Letrán, celebrado en Roma entre 1215 y 1216, en el que se trataron temas morales, relativos a la fe y también otros que tuvieron consecuencias políticas y económicas a partir de la condena a las herejías.

${ }^{35}$ MATEO 10: 28.

${ }^{36}$ JUAN 12: 25.

${ }^{37}$ SABIDURÍA 3: 1.

${ }^{38}$ ROMANOS 8:16.
} 
De modo que ella no es por sí en el sentido que existiría por sí misma, sin recibir de Dios su ser, sino que es por sí en el sentido que su ser no es el de un accidente. De ello no se deriva que el alma no dependa del cuerpo, pues depende igualmente de la materia. Así, todas las formas substanciales dependen de Dios, sin embargo, no son accidentes de Dios ni del universo.

La inmortalidad del alma es entonces una proposición cuya verdad es posible, probable e igualmente más probable que la proposición contraria. No obstante, en coherencia con el Doctor Sutil, para fray Juan de Fuica la inmortalidad del alma no puede probarse demostrativamente. Al respecto escribe: "Nótese que no son dadas razones naturales demostrativas que prueben la inmortalidad del alma".

Finalmente, el fraile de La Serena enseña que "las almas racionales son de desigual perfección individual". Sobre esto, explica que la razón de la desigualdad de las almas no es por causa de la multiplicidad de cuerpos desiguales que existen ni tampoco debido a la diversidad de órganos corpóreos, sino que, más bien, en esto ocurre al contrario: la perfección individual de cada alma racional es causa de la multiplicidad de cuerpos desiguales y de la diversidad de órganos corpóreos en los seres vivos.

\section{Conclusiones}

Los Comentarios a los tres libros Acerca del alma dictados por el franciscano chileno fray Juan de Fuica constituyen no sólo un testimonio único y exclusivo de la tradición escotista nacional de finales del siglo XVII, sino que además dan cuenta de la enseñanza filosófica de la época colonial.

El manuscrito del fraile de La Serena constituye el curso de animástica de autor chileno más antiguo del que tenemos noticia. Cabe señalar que es casi cincuenta años posterior a las Celebriores controversiae in Primum Sententiarum Ioannis Scoti (Madrid, 1638 y 1642), del también franciscano chileno Alonso Briceño (ca1587ca1668), quien como reconocimiento intelectual recibió entre sus pares los apelativos de Alter Scotus y Scotulus. Briceño es considerado uno de los primeros teólogos y filósofos hispanoamericanos y es mencionado en un par de ocasiones en el curso de Fuica.

Por otra parte, hallamos que la estructura de los contenidos presentados en los Comentarios posee características particulares que lo asemejan más al tratado aristotélico que al del Doctor Sutil. Y aunque el fraile no aborda las materias estudiadas en el libro primero por el Filósofo, incluye, en cambio, el estudio de temáticas propias de la psicología cristiana, ajenas completamente a las doctrinas aristotélicas. No obstante, de las veintitrés Quaestiones super secundum et tertium De anima de Escoto, en este curso del franciscano chileno se desarrollan los contenidos de veintidós de ellas, con excepción de la cuestión once, aunque no se conservan los títulos originales utilizados por el Sutil. 
En los Comentarios, el fraile expone los contenidos animásticos característicos de la enseñanza escolástica ad mentem Scoti, los que se corresponden con aquellos propios de la psicología racional.

En términos generales, vemos que las enseñanzas psicológicas se fundamentan en dos importantes doctrinas del Sutil. Por un lado, en la distinción metafísica ex natura rei entre el orden de la formalidad y el orden real, vale decir, en una novedosa división intermedia entre las distinciones real y de razón planteadas por Aristóteles. Así, esta interpretación de Escoto permite al fraile chileno afirmar que la unidad del alma contiene una pluralidad de formas distintas formalmente ex natura rei. Y, por otro lado, se fundamentan en la "célebre" noción de forma de corporeidad [forma corporetitatis], concepto central en la doctrina del Sutil que sustenta la particular organización del compuesto materia-forma. En esta línea vemos, por ejemplo, cómo fray Juan de Fuica explica los errores de Santo Tomás y sus discípulos en esta fundamental cuestión.

Aunque la fecha de redacción del curso (1689) indicaría que en él se expone una mentalidad juvenil, propia de los inicios del magisterio del fraile $-\mathrm{y}$ en donde prima la argumentación teológica por sobre la filosófica-, creemos que los Comentarios son un buen ejemplo de un curso introductorio para los frailes que posteriormente continuarían con los estudios teológicos. En ellos queda constancia de que el franciscano chileno estaba al tanto de los temas fundamentales de los grandes pensadores escolásticos, así como de las disputas y controversias teóricas de sus contemporáneos -sobre todo españoles- acerca de determinados conceptos filosóficos y teológicos centrales, como, por ejemplo, la noción de forma de corporeidad.

En un sentido aún más preciso, si bien en el curso apreciamos errores ortográficos y gramaticales que no garantizarían una revisión cuidadosa de los textos, nos inclinamos a pensar que el libro que reúne los comentarios del trienio 1687-1689 podría ser el esfuerzo del fraile por responder a las demandas internas de la orden de unificar las materias requeridas por los estudiantes de artes. De este modo, el libro podría constituir un esbozo para un eventual Manual de estudios de la Provincia chilena.

En todo caso, y de no ser así, el curso de animástica de fray Juan de Fuica constituye inapelablemente un testimonio único de la enseñanza de la filosofía franciscana de la época. Su estudio nos permite visibilizar el patrimonio filosófico colonial del país y, en consecuencia, llenar una gran laguna en la historia de la filosofía chilena. 


\section{Referencias bibliográficas}

Actas del Definitorio, Volumen III (1714-1735). Archivo de la Provincia Franciscana, Santiago de Chile.

ARISTÓTELES. Acerca del alma. Introducción, traducción y notas de Tomás Calvo Martínez. Madrid: Gredos, 1999.

ARISTÓTELES. Metafísica. Edición trilingüe por Valentín García Yebra. Madrid: Gredos, 1970.

ARISTÓTELES. Reproducción de los animales. Introducción, traducción y notas de Ester Sánchez. Madrid: Gredos, 1994.

ASTORQUIZA Pizarro, Fernando. Bio-Bibliografia de la filosofia en Chile desde el siglo XVI hasta 1980. Santiago de Chile: Barcelona Empresa Industrial Gráfica, 1982.

CAZANOVA, Fr. Francisco. Historia de la Recoleta I. Santiago de Chile: Publicaciones del Archivo Franciscano, no 56, 1998.

DONOSO, Ricardo. "Inventario de la Colección del Fondo Antiguo del Archivo Nacional de Santiago de Chile". Handbook of Latin American Studies, pp. 547-572, 1937.

ESPEJO, Juan Luis. Nobiliario de la Antigua Capitanía General de Chile. Santiago de Chile: Imprenta Universitaria, 1917.

FUENZALIDA, Alejandro. Historia del desarrollo intelectual en Chile (1541 1810). (Enseñanza Pública i Cultura Intelectual). Santiago de Chile: Imprenta Universitaria, 1903.

FUICA, Juan de. Commentaria phylosophica ad mentem Doctoris Subtilissimi Patris Fratris Joannis Duns Scoti Sacratissimi Ordinis Minorum et Theologorum Principis. Santiago de Chile, 1687, 592p, Archivo Histórico Franciscano, original, Ms.

FUICA, Juan de. Commentaria in tres libros De anima ad mentem nostri Subtilis Doctoris Duns Scoti, Theologorum Principis. Santiago de Chile, 1689, 48p [545-592], Archivo Histórico Franciscano, original, Ms.

HANISCH Espíndola, Walter. En torno a la Filosofía en Chile (1594 - 1810). Santiago de Chile: Ediciones Historia, Universidad Católica de Chile, 1963.

Informes de Novicios (1603 - 1739). Archivo de la Provincia Franciscana, Santiago de Chile.

ITURRIAGA, Rigoberto. El Colegio San Diego de Alcalá. Santiago de Chile: Publicaciones del Archivo Franciscano, no 4, 1990.

ITURRIAGA, Rigoberto. "El Escotismo en Chile". Anuario de Historia de la Iglesia en Chile. Santiago de Chile: Seminario Pontificio Mayor, V. 8, pp. 37-58, 1990.

ITURRIAGA, Rigoberto. Tablas Capitulares de la Provincia Franciscana (XVII). Santiago de Chile: Publicaciones del Archivo Franciscano, nº 69, 2001. 
MEDINA, José Toribio. La Instrucción Pública en Chile desde sus orígenes hasta la fundación de la Universidad de San Felipe. Santiago de Chile: Imprenta Elzeviriana, 2 volúmenes, 1905.

MEDINA, José Toribio. Historia de la Real Universidad de San Felipe de Santiago de Chile. Santiago de Chile: Imp. y Lit. Universo. 2 Tomos, 1928.

QUILES, Ismael. «Manuscritos filosóficos en la época colonial en Chile». Ciencia y $F e$, pp. 39-61, 1953.

RAMÍREZ, Hugo. Fuentes para la historia franciscana II. Libros Becerros de Actas y Decretos del Venerable Definitorio de la Provincia Franciscana de la Santísima Trinidad de Chile. Índice de Materias y Extractos. Siglo XVIII (1700-1734). Santiago de Chile: Publicaciones del Archivo Franciscano, $\mathrm{n}^{\circ}$ 23, 1992.

RAMÍREZ, Hugo. Fuentes para la historia franciscana IV. Libros Becerros de Actas y Decretos del Venerable Definitorio de la Provincia Franciscana de la Santísima Trinidad de Chile. Índice de Materias y Extractos. Siglo XVIII (1765-1799). Santiago de Chile: Publicaciones del Archivo Franciscano, ${ }^{\circ}$ 29, 1993.

REDMOND, Walter. Bibliography of the Philosophy in the Iberian Colonies of America. The Hague: Martinus Nijhoff, 1972.

SCOTUS, I. Opera Omnia (Editio Vaticana). Civitas Vaticana: Typis Polyglottis Vaticanis, 1950-2013.

SONDAG, Gérard. "Jean Duns Scot sur la connaissance intuitive intellectuelle (Cognitio Intuitiva)". Veritas: Revista de Filosofía (Porto Alegre), v. 53, pp. 32-58, 2008.

VALENZUELA, Pedro Armengol. Los Regulares en la Iglesia y en Chile. Roma: Imprenta Tiberina de Federico Setth, 1900.

Abel Aravena Zamora

Universidad de Barcelona, España.

abelot1@hotmail.com 